\title{
A EDUCAÇÃO DEMOCRÁTICA EM TEMPOS DE "ESCOLA SEM PARTIDO"
}

\author{
DEMOCRATIC EDUCATION IN “NON-PARTISAN SCHOOL” TIMES
}

\section{LA EDUCACIÓN DEMOCRÁTICA EN TIEMPOS DE "ESCUELA SIN PARTIDO”}

\author{
Charles Immianovsky \\ Fundação Universidade de Blumenau - FURB - Brasil \\ Rita de Cássia Marchi \\ Fundação Universidade de Blumenau - FURB - Brasil \\ Carla Carvalho \\ Fundação Universidade de Blumenau - FURB - Brasil
}

\begin{abstract}
Resumo: Este texto aborda autores que tratam das relações entre educação, sociedade e democracia, além de normas constitucionais e infraconstitucionais da legislação brasileira, com o objetivo de desenvolver a ideia de uma educação democrática e, assim, problematizá-la frente à organização Escola sem Partido (EsP). Busca-se demonstrar que a educação democrática é um princípio inegociável em uma democracia. No entanto, com o golpe de Estado de 2016 e a intensificação das ações da organização EsP, princípios basilares como os relacionados à educação democrática foram colocados em dúvida e, por isso, necessitam ser constantemente defendidos e reafirmados.
\end{abstract}

Palavras chave: Educação democrática; Escola sem Partido; Sociedade.

\begin{abstract}
This text addresses authors who deal with the relationship between education, society and democracy, as well as constitutional and infraconstitutional norms of the Brazilian legislation, with the objective of developing the idea of a democratic education and, thus, problematizing it before the nonpartisan school organization. It seeks to demonstrate that democratic education is a non-negotiable principle in a democracy. However, with the 2016 State coup and the intensification of the actions of the non-partisan school organization, basic principles such as those related to democratic education were put in doubt and, therefore, they need to be constantly advocated and reaffirmed.
\end{abstract}

Keywords: Democratic education; Non-partisan school; Society.

Resumen: Este texto abarca autores que se tratan de las relaciones entre educación, sociedad y democracia, además de las normas constitucionales e infraconstitucionales de la legislación brasileña, con el objetivo de desarrollar la idea de una educación democrática y, por lo tanto, problematizarla frente a la organización Escuela sin Partido (EsP). Se busca demostrar que la educación democrática es un principio no negociable en una democracia. Sin embargo, con el golpe de estado de 2016 y la intensificación de las acciones de la organización EsP, principios básicos como los relacionados con la educación democrática se pusieron en duda y, por ello, necesitan ser constantemente defendidos y reafirmados.

Palabras clave: Educación democrática; Escuela sin Partido; Sociedad. 


\title{
Palavras iniciais
}

\author{
Irmão de olho claro ou da Guiné \\ Qual será o seu valor? \\ Pobre artigo de mercado \\ Senhor, eu não tenho a sua fé e nem tenho a sua cor \\ Tenho sangue avermelhado \\ O mesmo que escorre da ferida \\ Mostra que a vida se lamenta por nós dois \\ Mas falta em seu peito um coração \\ Ao me dar a escravidão e um prato de feijão com arroz \\ Eu fui mandiga, cambinda, haussá \\ Fui um Rei Egbá preso na corrente \\ Sofri nos braços de um capataz \\ Morri nos canaviais onde se plantava gente. \\ $\hat{E}$ calunga! $\hat{E} \hat{e}$ calunga! \\ Preto velho me contou, preto velho me contou \\ Onde mora a senhora liberdade \\ Não tem ferro, nem feitor. \\ Meu Deus! Meu Deus! \\ Se eu chorar não leve a mal \\ Pela luz do candeeiro \\ Liberte o cativeiro social
}

Se a garantia de uma educação pública de qualidade e democrática é uma conquista expressa na Constituição Federal de 1988 e a luta pela sua efetivação um desafio reconhecido no campo educacional, diversos autores, recentemente, (MOTTA; FRIGOTTO, 2017; CUNHA, 2017; FERRETI; SILVA, 2017) têm alertado para a intensificação deste desafio.

Estes autores alertam sobre a recente imposição de alterações na Constituição Federal e uma pauta de reformas que provocam modificações estruturais no sistema de ensino público brasileiro com impacto sobre a efetivação de uma educação pública, universal, gratuita, laica e de qualidade. Dentre estas alterações e reformas estes autores destacam: a Emenda Constitucional n. ${ }^{\circ} 95$, de 15 de dezembro de $2016^{2}$, a Lei n. ${ }^{\circ} 13.365$, de 29 de novembro de

\footnotetext{
${ }^{1}$ Fragmento de samba enredo do Grêmio Recreativo Escola de Samba Paraíso do Tuiuti. Carnaval de 2019.

${ }^{2}$ A Emenda Constitucional $n^{\circ}$ 95/2016 e a Lei $n .^{\circ} 13.365$, juntas, impedem o financiamento de novas políticas educacionais e a ampliação ou manutenção de muitas já existentes. A primeira, conhecida como a "PEC do Fim do Mundo", agrava a situação por congelar por um período de vinte anos os gastos públicos direcionados à educação e demais áreas sociais; a segunda, por aprovar a privatização do Pré-sal e do Regime de Partilha, compromete a aplicação de investimentos na educação.
} 
2016 e a Lei n. ${ }^{\circ} 13.415$, de 16 de fevereiro de $2017^{3}$. Além dessas reformas e alterações constitucionais já realizadas, pesquisadores (FRIGOTTO, 2017; PENNA, 2017; TOMMASELLI, 2018) também acautelam para uma 'nova' ameaça (no campo ideológico) à educação brasileira, a Escola sem Partido (EsP), especialmente no que se refere ao caráter democrático desta educação. Diante destes fatos, o mote deste texto é problematizar a educação democrática diante da organização $\mathrm{EsP}^{4}$.

A EsP, criada em 2004 pelo advogado paulistano Miguel Nagib, se apresenta como uma iniciativa apartidária de alguns pais e estudantes que se dizem preocupados com uma suposta contaminação político-ideológico nas escolas e universidades brasileiras. O principal objetivo da organização é combater esta suposta doutrinação ideológica, a qual violaria, segundo seu criador, a liberdade de crença e consciência dos estudantes.

A iniciativa parecia não ter condições de prosperar, dada sua inconsistência teórica e jurídica (QUEIROZ; OLIVEIRA, 2018), verificada na decisão liminar do ministro Luís Roberto Barroso, do Supremo Tribunal Federal (STF), em 2017, na Ação Direita de Inconstitucionalidade $\mathrm{n}^{\circ} 5537$ (ADI 5537) ajuizada pela Confederação Nacional dos Trabalhadores de Estabelecimento de Ensino (Contee). Na decisão, o ministro apontou a inconstitucionalidade da Lei $\mathrm{n}^{\circ} 7.800 / 2016$, do estado de Alagoas, sedimentada nas propostas da organização EsP, suspendendo assim os efeitos da lei. E, em sessão virtual realizada de 17/04/2020 a 24/4/2020, no julgamento da Arguição de Descumprimento de Preceito Fundamental 457 (ADPF 457) proposta pela Procuradoria Geral da República (PGR) em 2017, o Plenário do Supremo Tribunal Federal se posicionou na mesma direção ao considerar, em decisão unânime, inconstitucional outra lei sedimentada nas propostas da EsP. A decisão é referente à Lei $n^{\circ}$ 1.516/2015 do Município de Novo Gama (GO) que proibiu a utilização de materiais didáticos que abordem questões de gênero e sexualidade nas escolas públicas municipais.

Porém, as articulações desta organização com grupos conservadores da sociedade civil e com grupos políticos conservadores lhe deu capilaridade. Isto foi possível a partir do momento em que a EsP fundiu o tema inicial (a "doutrinação ideológica marxista") com o combate à "ideologia de gênero", se aproveitando de uma forte onda conservadora que tomou vulto em nosso país após as manifestações de 2013 (TOMMASELLI, 2018). As “jornadas de junho de

\footnotetext{
${ }^{3}$ Quanto à Lei n. ${ }^{o} 13.415 / 2017$, ela altera estruturalmente o currículo do ensino médio e ataca a concepção políticopedagógica da educação pública; o objetivo da reforma é, supostamente, a "flexibilização do currículo", mas, na verdade, ela retoma "[...] a antiga concepção do Ensino Médio como preparação para o Ensino Superior para uns, e formação para o trabalho para outros." (CUNHA, 2017, p. 379).

${ }^{4}$ Adota-se a categoria "organização" em detrimento de "movimento" a partir do estudo de Algebaile (2017) para o qual a EsP se enquadra nas características de uma organização.
} 
2013", como ficaram conhecidas, apresentaram elementos como o apartidarismo e a antipolítica, pautados na agressão aos partidos políticos, e que se desenvolveriam nos anos seguintes, conduzindo à narrativa do golpe de Estado de 2016 que levou à deposição da então presidente Dilma Rousseff, legitimamente eleita no pleito de 2014. Este é o cenário inicial que favoreceu especialmente a EsP, porque o "sucesso" e a "federalização" das manifestações de junho de 2013 instauraram maior proximidade entre segmentos conservadores do cenário brasileiro. (TOMMASELLI, 2018).

Assim, aproveitando da polarização no campo político, ao adaptar sua pauta, a organização obteve apreço dos grupos políticos conservadores e avançou com o objetivo de incluir o Programa Escola sem Partido $^{6}$ na legislação educacional brasileira. De forma crescente, projetos de lei sedimentados neste Programa começaram a tramitar na Câmara Federal dos Deputados, nas assembleias legislativas estaduais e nas câmaras municipais. ${ }^{7}$ Neste sentido, a EsP agregou-se ao contexto de ofensivas conservadoras, autoritarismo e retrocesso de conquistas sociais que caracterizam o atual momento político brasileiro (MELO, 2017).

As alterações constitucionais, as reformas e as crescentes ações da EsP reforçam a compreensão de que o "[...] golpe de Estado perpetrado contra a Constituição Federal e a democracia no Brasil em 2016 [...] deu início a um gigante processo de retrocesso dos direitos econômicos e sociais do povo brasileiro" (PRONER; STROZAK, 2017, p. 14). É justamente no contexto do golpe de Estado e de retrocessos de muitos direitos econômicos e sociais que a EsP se manifesta como uma 'nova' ameaça à educação brasileira, colocando em suspensão o sentido ou valor de uma educação democrática.

Diante do exposto, busca-se demonstrar princípios estabelecidos já desde o século XIX, entre educação, sociedade e democracia, e que estão refletidos e ampliados na legislação educacional brasileira. No entanto, em tempos de EsP, corre-se o risco destes princípios serem colocados em dúvida ou suspensão. Por isso, este texto problematiza a ideia de uma educação democrática diante da EsP, afirmando que se trata de um conceito inegociável numa democracia. Busca-se, então, demonstrar o antagonismo dos objetivos, das ideias e dos modos de atuação da EsP com os princípios democráticos, com os direitos e com as garantias fundamentais no campo da Educação.

\footnotetext{
${ }^{5} \mathrm{O}$ termo expressa o processo de transferência das manifestações (localizadas) de 2013 para todo o país.

${ }^{6}$ O Programa Escola sem Partido é uma proposta de lei baseada nas ideias da EsP que quer tornar obrigatória, entre outras coisas, a afixação de um cartaz intitulado "Deveres do professor" em todas as salas de aula do ensino fundamental e médio.

${ }^{7}$ O PL no $7180 / 2014$ apensado ao PL $n^{\circ} 867 / 2015$ e o PL n ${ }^{\circ} 1.411 / 2015$ são os primeiros projetos coma as proposições e ideias da EsP que ganharam destaque na Câmara Federal.
} 


\section{Educação e democracia}

A emergência da sociedade moderna e da ascensão da burguesia como classe social revolucionária marcam a gênese histórica da atual forma escolar, contexto no qual " [...] a escola foi erigida em forma principal e dominante de educação.” (SAVIANI, 1992, p. 11).

Quanto ao caráter revolucionário da burguesia, Saviani (1991, p. 50) esclarece que:

[...] toda postura revolucionária é uma postura essencialmente histórica, é uma postura que se coloca na direção do desenvolvimento da história. Ora, naquele momento, a burguesia se colocava na direção do desenvolvimento da história e seus interesses coincidiam com os interesses do novo, com os interesses da transformação; e é nesse sentido que a filosofia da essência, que vai ter depois como consequência a pedagogia da essência, vai fazer uma defesa intransigente da igualdade essencial dos homens. Sobre essa base da igualdade dos homens, de todos os homens, é que se funda então a liberdade, que se vai postular a reforma da sociedade.

A burguesia, enquanto classe revolucionária, advogou pela filosofia da essência como meio para a defesa da igualdade de todos os homens, sendo por meio desta que esta classe acionou a crítica à nobreza e ao clero. A crítica questionava a dominação não-natural e nãoessencial que as duas classes dominantes à época buscavam legitimar, o que significava "[...] colocar diante da nobreza e do clero a ideia de que as diferenças, os privilégios de que eles usufruíam, não eram naturais e muito menos divinos, mas eram sociais." (SAVIANI, 1991, p. 51). Portanto, se as diferenças e os privilégios da nobreza e do clero decorriam de fatores sociais e não naturais ou divinos, estes se configuravam como injustiças. Assim sendo, não poderiam continuar existindo, devendo ser superados, o que demandava a substituição daquela sociedade (a feudal), fundada em senhores e servos, por uma sociedade igualitária (SAVIANI, 1991).

Em busca de uma sociedade igualitária, a burguesia advogará a escolarização para todos, como meio de converter os servos em cidadãos, daí porque em meados do século XIX se estruturarão os sistemas nacionais de ensino. Esta conversão era condição para que estes participassem “[...] do processo político, e, participando do processo político, eles consolidariam a ordem democrática, democracia burguesa, é obvio, mas o papel político da escola estava aí muito claro. A escola era proposta como condição para a consolidação democrática." (SAVIANI, 1991, p. 51-52). O interesse era consolidar a democracia burguesa, como forma de superar a opressão do Antigo Regime, o que demandava vencer a barreira da ignorância, transformando os súditos em cidadãos. Assim, "o direito de todos à educação decorria do tipo de sociedade correspondente aos interesses da nova classe que se consolidava no poder: a burguesia." (SAVIANI, 1991, p. 17). 
Além disto, como a sociedade capitalista estava baseada na relação contratual, Saviani (1992, p. 12) destaca que, "[...] o domínio de uma cultura intelectual, cujo componente mais elementar é o alfabeto, se impõe como exigência generalizada de participação ativa na referida sociedade". Então, a escola se transforma no principal instrumento que viabiliza o acesso sistematizado à cultura da linguagem escrita, como sintetiza Saviani (1992, p. 12-13):

[...] ao deslocamento do eixo do processo produtivo do campo para a cidade, da agricultura para a indústria; ao deslocamento do eixo do processo cultural do saber espontâneo, assistemático para o saber metódico, sistemático, científico, correspondeu o deslocamento do eixo do processo educativo de formas difusas, identificadas com o próprio processo de produção da existência, para formas específicas e institucionalizadas, identificadas com a escola.

Deste modo, pode-se aferir que o surgimento da escola na forma que a conhecemos hoje foi marcado pelo tipo de sociedade decorrente das alterações no processo de produção, na passagem do feudalismo para o capitalismo. A burguesia consolidava suas ideias enquanto classe revolucionária ao mesmo tempo que socializava a todos os valores da nova ordem social. Por isso, para manter o controle, esta classe social irá “[...] em meados do século passado, estruturar os sistemas nacionais de ensino e advogar a escolarização para todos" (SAVIANI, 1991, p. 51). Em síntese, a escola deixou de ser um privilégio das elites

[...] na medida em que ocorrem mudanças significativas na produção e organização da vida social, na passagem do feudalismo para o capitalismo, com o surgimento do liberalismo, diante da necessidade de operar as forças produtivas que estavam em desenvolvimento, a nova classe dominante que surgiu, a burguesia, para poder se desenvolver, foi forçada a, paulatinamente, abrir mão de sua exclusividade e começar a 'socializá-la'. Assim surge a escola pública, que se amplia progressivamente a partir da Revolução Francesa até os dias atuais. (ORSO, 2019, p. 131-132).

Mas, "socializar" a escola criou, para a burguesia, o problema de expandi-la ou tornála acessível para os trabalhadores sem que o conhecimento por ela difundido pudesse se converter em instrumento contrário a seus interesses, ou seja, sem que a nova ordem existente pudesse ser subvertida, uma vez que, de classe revolucionária, a burguesia transformou-se em classe dominante. A educação, então, institucionalizada e difundida por meio da escola, também deveria ser o principal instrumento para garantir a nova ordem social e impedir a propagação de ideias revolucionárias.

No campo teórico, é a corrente sociológica funcionalista que se encarregará da tarefa de formular um modelo de educação que garantisse, por um lado, educação para todos e por outro mantivesse, consolidando, a nova ordem social. E é a obra Educação e Sociologia (1922), 
de Durkheim, que receberá destaque dentro da corrente funcionalista.

Para Durkheim a escola desempenha um papel fundamental na sociedade, pois é através da educação, definida por ele como “[...] a acção exercida pelas gerações adultas sobre aquelas que ainda não estão maduras para a vida social" (DURKHEIM, 2001, p. 52), que a escola prepararia as gerações para a vida social e garantiria a ordem social. Assim, a escola prepararia as novas gerações para a vida social e garantiria a sua ordem. Por isso, para ele, a educação "[...] tem por objecto suscitar e desenvolver na criança um certo número de estados físicos, intelectuais e morais que lhe exigem a sociedade política no seu conjunto e o meio especial ao qual está particularmente destinada.” (DURKHEIM, 2001, p. 52). Nesse sentido, já podemos perceber nesse postulado inicial de Durkheim o desenho ou projeto do que viria a ser o modelo dual de educação que vivenciamos até os dias atuais: uma educação não é a mesma nem igual para todos. Isto porque a teoria da socialização deste autor centra-se sobre dois processos distintos, mas complementares: a integração social e a regulação social. Ambos processos são necessários para a nova classe dominante (a burguesia) se manter como tal. Assim, por um lado, era preciso que o conjunto de ideias e sentimentos que estivessem de acordo com a perpetuação dos interesses desta classe fosse inculcado nos novos membros da sociedade, isto é, que as novas gerações fossem socializadas tendo por norte os valores da burguesia, pois isto garantiria a coesão social através da integração dos indivíduos aos valores do conjunto da sociedade. Mas, ao mesmo tempo, era preciso também regular e harmonizar os comportamentos destes novos membros no interior da estrutura hierárquica da sociedade de classes: a existência desta estrutura deveria ser aceita como justa ou legítima e as paixões ou aspirações socialmente adaptadas para cada indivíduo segundo o seu lugar nesta estrutura: de um lado os detentores do capital e de outro os trabalhadores com sua força de trabalho. (DUBAR, 2000; FRIGOTTO, 2018).

Decorre dessa nova conjuntura os dois momentos distintos na formação do indivíduo preconizados por Durkheim. Assim, num primeiro momento a educação deve buscar inculcar nas crianças um conjunto de ideias e sentimentos comuns que estariam

[...] na base da nossa civilização, um certo número de princípios que, implícita ou explicitamente, são comuns a todos ou, pelo menos, que poucos ousam negar abertamente e face a face: respeito pela razão, pela ciência, pelos ideais e sentimentos que estão na base da moral democrática. O papel do Estado é esclarecer esses princípios essenciais, fazê-los ensinar nas suas escolas, velar para que em nenhum lugar as crianças os ignorem, e para que em todo o lado se fale deles com o respeito que lhe é devido. (DURKHEIM, 2001, p. 61-62).

Num segundo momento, o que seria comum é substituído por especificidades a fim de garantir para cada indivíduo a educação necessária para que este se adapte ao meio social ao 
qual estaria destinado a viver; neste momento a educação já não deveria ser a mesma para todos, mas definida em função dos meios específicos para os quais cada qual esteja destinado, de modo a garantir a sobrevivência (e a reprodução) do conjunto social. Assim, afirmava Durkheim que a educação

[...] da cidade não é a do campo, a do burguês não é a do operário. Cada profissão, com efeito, constitui um meio sui generis que reclamam aptidões particulares e conhecimentos especiais, onde reinam certas ideais, certos usos, certas maneiras de ver as coisas; e como a criança deve ser preparada tendo em vista a função que será chamada a desempenhar, a educação, a partir de uma certa idade, não pode mais continuar a ser a mesma para todas as crianças às quais ela se destina. (DURKHEIM, 2001, p. 50, grifo do autor).

Destaca-se também que Durkhein dá centralidade ao papel do Estado como garantidor da educação para todos. O Estado então, garantiria a formação necessária para que o indivíduo das novas gerações se adaptasse ao meio social em que estaria destinado a viver. Nessa lógica, a ideia era a da garantia da nova ordem social e do novo sistema político, a democracia burguesa.

Como Durkheim não está interessado em problematizar as diferenças sociais geradas pela sociedade capitalista, seu interesse se volta para a socialização metódica dos conhecimentos e valores, o que permitirá formar o "ser social" que Durkheim (2001) define como distinto do ser individual:

Em cada um de nós, podemos dizê-lo, existem dois seres que, apesar de apenas poderem ser separáveis por abstração, não deixam de ser distintos. Um é feito de todos os estados mentais que apenas se ligam a nós mesmos aos acontecimentos da nossa vida pessoal: é o que podemos achar o ser individual. O outro é um sistema de ideias, de sentimentos e de hábitos que exprimem em nós, não a nossa personalidade, mas o grupo ou os grupos diferentes de que fazemos parte: as crenças religiosas, as crenças e as práticas morais, as tradições nacionais ou profissionais, as opiniões colectivas de qualquer gênero. O seu conjunto forma o ser social. Constituir este ser em cada um de nós, tal é o fim da educação. (DURKHEIM, 2001, p.53).

Desenvolver o ser social é, portanto, premissa para o desenvolvimento harmonioso da sociedade, por isso, o foco na ação que os adultos devem exercer sobre os mais jovens como forma de garantir a sua integração à sociedade. Por isto, em Durkheim, a maior atenção será dada à ação sócio pedagógica, pois, através dela será possível imprimir, nas crianças, um conjunto de elementos morais e intelectuais de forma harmoniosa com a estrutura social do momento. (PETITAT, 1994). Garantida essa ação educacional, os mais jovens, quando adultos, estariam aptos a conviver em determinada sociedade, fazendo com que ela "funcionasse" harmonicamente. 
Portanto, fica explícita a estreita relação, para Durkheim, entre sociedade e educação, na qual a primeira deve estar atenta e interessada no desenvolvimento da segunda, de modo a não colocar em risco a busca pela coesão social e a garantir a função coletiva da educação e o papel que nela a sociedade desempenha:

[...] a educação tem, antes de mais, uma função colectiva, se ela tem por objecto adaptar a criança ao meio social onde está destinada a viver, é impossível que a sociedade se desinteresse de uma tal operação. Como poderá ela estar ausente, uma vez que é o ponto de referência a partir do qual a educação deverá dirigir a sua ação? [...] Se não estivesse sempre presente e vigilante para obrigar a acção pedagógica a exercer-se num sentido social, esta colocar-se-ia necessariamente ao serviço de crenças particulares, e a grande alma da pátria dividir-se-ia e decompor-se-ia numa quantidade incoerente de pequenas almas fragmentárias em conflito umas com as outras. Não se pode ir mais completamente contra o objectivo fundamental de qualquer educação. É preciso escolher: se damos algum valor à existência da sociedade [...] é necessário que a educação assegure entre os cidadãos uma comunhão de ideias e de sentimentos sem os quais qualquer sociedade é impossível; e para que possa produzir este resultado, é ainda necessário que não seja abandonada totalmente à arbitrariedade dos particulares. (DURKHEIM, 2001, p. 60).

A ação pedagógica, portanto, é que garante que a sociedade imprima sobre cada indivíduo um conjunto de ideias, sentimentos e hábitos que se sobrepõe às crenças ou desejos particulares. Do contrário, não seria possível produzir o 'ser social' e garantir o funcionamento e sobrevivência de uma determinada sociedade: "A sociedade só pode subsistir se existir entre os membros uma homogeneidade suficiente; a educação perpetua e reforça esta homogeneidade fixando com antecedência na alma da criança as similitudes essenciais que a vida colectiva exige" (DURKHEIM, 2001, p. 52).

Deste modo, a atual forma escolar, embora nascida sob o signo republicano (laicidade e universalização), sofre críticas em relação à sua constituição, entre as quais se destacam: (1) no momento que passa de classe revolucionária para classe consolidada no poder, os interesses da burguesia caminham não mais para a transformação da sociedade, mas para a manutenção desta, ou seja, ela deixa a linha do desenvolvimento histórico, voltando-se contra a própria história (SAVIANI, 1991); (2) a intenção de universalização da educação burguesa não se realizou, pois nem todos nela ingressavam e nem todos que ingressavam e eram bem-sucedidos ajustavam-se ao tipo de sociedade que se queria consolidar (SAVIANI, 1991); (3) o caráter dual desse modelo de educação, uma escola que desenvolve conhecimentos, valores e atitudes para os que irão dirigir, organizar e comandar, e uma escola restrita, para os que se destinam ao trabalho manual ou de execução (FRIGOTTO, 2018).

Porém, para além das críticas à escola burguesa que, progressivamente, se revelou uma crescente decepção, seja pela não efetiva universalização da educação ou pelo modelo dual de 
educação que instalou, é necessário reconhecer que foi a sociedade moderna que legou às sociedades ocidentais princípios basilares que influenciariam o desenvolvimento da ideia de uma educação democrática, a saber: a educação para todos como um direito social a ser assegurado pelo Estado; a escola como forma principal e dominante de educação; e o papel da sociedade e do Estado na garantia de um conjunto essencial de conhecimentos e valores às novas gerações que se sobrepõe aos valores particulares.

Considerando o exposto, e antes de problematizar a educação democrática diante das propostas, objetivos e ações da EsP, busca-se demonstrar brevemente, na sequência, como estes princípios fundamentais se incorporaram à legislação educacional brasileira.

\section{A educação democrática no Brasil}

Inicialmente, se ressalta que o direito à educação pública que se consolidou na legislação brasileira, e que será brevemente demonstrado, é resultado do engajamento e da luta dos educadores brasileiros durante décadas. Esta luta que ainda não terminou e que parece atualmente se intensificar, segundo alguns elementos anunciados na introdução deste texto, já atravessa um século e é assim sintetizada nas palavras de Saviani:

Efetivamente, a luta dos educadores pela qualidade da educação pública começa na década de 1920, com a fundação da Associação Brasileira de Educação (ABE), em 1924; adquire visibilidade com o lançamento do Manifesto dos Pioneiros da Educação Nova, em 1932, e com a Campanha em Defesa da Escola Pública, na virada da década de 1950 para os anos de 1960, na fase final da tramitação do projeto de LDB; prossegue com as Conferências Brasileiras de Educação da década de 1980 e com o Fórum Nacional em Defesa da Escola Pública na Constituinte e na nova LDB; desemboca na elaboração da proposta alternativa de Plano Nacional de Educação nos Congressos Nacionais de Educação de 1996 e 1997; e se mantém com grandes dificuldades neste início do século XXI, na forma de resistência às políticas e reformas em curso e na reivindicação por melhores condições de ensino e de trabalho para os profissionais da educação. (2007, p. 1243).

Nos anos 80, o processo de redemocratização do país, após vinte e um anos de Ditadura Militar (1964-1985), culminou na formulação da Constituição Federal de 1988 (também conhecida como “Constituição cidadã”), construída com a participação da sociedade civil. Tal fato contribuiu para fortalecer o princípio democrático, mostrando que o país, ao longo de sua formação, optava pela democracia. A nova ordem jurídica tratará de estabelecer o princípio democrático como norteador de todo o texto constitucional e de estabelecer como fundamental e imprescindível o princípio da dignidade da pessoa e da cidadania, como deixa explícito o artigo $1^{\circ}$ da atual Constituição: 
Art. $1^{\circ}$ A República Federativa do Brasil, formada pela união indissolúvel dos Estados e Municípios e do Distrito Federal, constitui-se em Estado Democrático de Direito e tem como fundamentos:

[...]

I - a cidadania;

II - a dignidade da pessoa humana; (BRASIL, 1988).

Quanto ao tema educação, o artigo $6^{\circ}$ estabelecerá a educação como direito fundamental público subjetivo, considerando-o como um direito social. Corroborará com o artigo $6^{\circ}$ o texto do artigo 205 , que define:

Art. 205. A educação, direito de todos e dever do Estado e da família, será promovida e incentivada com a colaboração da sociedade, visando ao pleno desenvolvimento da pessoa, seu preparo para o exercício da cidadania e sua qualificação para o trabalho. (BRASIL, 1988).

Destaca-se do artigo 205 que a educação é um direito de todos e dever do Estado, sendo que a promoção e o incentivo desta deverá ter a colaboração da sociedade e ter, entre seus objetivos, o preparo para a cidadania. Queiroz e Oliveira (2018) ainda reparam que diante do artigo 205 fica evidenciado que para a Constituição Federal de 1988 a educação deve garantir o desenvolvimento pleno da pessoa para que esta possa efetivamente exercer sua participação democrática na sociedade:

Repare que o texto do artigo 205 estabelece que a educação no Brasil tenha como objetivo o pleno desenvolvimento da pessoa, pois daí decorrerá sua condição de cidadã e, assim, o outro objetivo estatuído no texto, que é o preparo para o exercício da cidadania. Sem um desenvolvimento pleno da pessoa fica prejudicado o exercício da cidadania e, consequentemente, inviabiliza-se a efetiva participação democrática. (QUEIROZ; OLIVEIRA, 2018, p. 40).

A legislação citada está em consonância com o tratado internacional dos Direitos Humanos do qual o Brasil é signatário. Na Declaração Universal dos Direitos Humanos, de 1948, fica estabelecido no artigo 26 que:

1. Todo ser humano tem direito à instrução. A instrução será gratuita, pelo menos nos graus elementares e fundamentais. A instrução elementar será obrigatória. A instrução técnico-profissional será acessível a todos, bem como a instrução superior, esta baseada no mérito.

2. A instrução será orientada no sentido do pleno desenvolvimento da personalidade humana e do fortalecimento do respeito pelos direitos do ser humano e pelas liberdades fundamentais. A instrução promoverá a compreensão, a tolerância e a amizade em todas as nações e grupos raciais ou religiosos e coadjuvará as atividades das nações Unidas em prol da manutenção da paz. (DECLARAÇÃO UNIVERSAL DOS DIREITOS HUMANOS, 2009, p. 14). 
Ainda, o artigo 206 da Constituição Federal, no capítulo que trata da educação, estatui:

Art. 206 O ensino será ministrado com base nos seguintes princípios:

[...]

II - liberdade de aprender, ensinar, pesquisar e divulgar o pensamento, a arte e o saber;

III - pluralismo de ideias e de concepções pedagógicas, e coexistência de instituições públicas e privadas de ensino; (BRASIL, 1988).

É o que também está presente na LDB nº 9.394/1996 que consolidou a luta dos educadores brasileiros por educação pública, gratuita e de qualidade ao prever a obrigação do Estado e da sociedade brasileira para com a formação das futuras gerações. O Art. $3^{\circ}$ da LDB n 9 9.394/1996 ratifica princípios do Art. 206 da Constituição Federal ao instituir a liberdade do ato de aprender e ensinar, pautado no pluralismo de ideias e concepções pedagógicas e amplia o texto constitucional incluindo princípios que reforçam o pleno desenvolvimento da pessoa para o exercício da cidadania e convívio em sociedade, como o respeito à liberdade e apreço à tolerância, e a consideração com a diversidade étnico-racial. Além disso, institui a valorização dos profissionais da educação escolar.

Art. $3^{\circ} \mathrm{O}$ ensino será ministrado com base nos seguintes princípios:

$[\ldots]$

II - liberdade de aprender, ensinar, pesquisar e divulgar a cultura, o pensamento, a arte e o saber;

III - pluralismo de ideias e de concepções pedagógicas;

IV - respeito à liberdade e apreço à tolerância;

$[\ldots]$

VII - valorização do profissional da educação escolar;

$[\ldots]$

XII - consideração com a diversidade étnico-racial. (BRASIL, 1996).

O conjunto dos artigos legais não deixa dúvidas o quanto o texto constitucional brasileiro resguarda princípios da sociedade moderna no tema educação, dadas as semelhanças que podem ser percebidas, especialmente quando fica evidenciada a intrínseca relação entre sociedade, educação e democracia. Dessas normas constitucionais e infraconstitucionais ecoa a garantia de uma educação plena, com atenção a uma formação integral da pessoa e com centralidade na dignidade humana, a ser desenvolvida com liberdade, pluralismo de ideias e de concepções pedagógicas. Esses princípios ecoam e encontram lugar nos sentidos fixados por Penna (2018, p. 128), para quem a educação democrática é: “[ ...] uma educação que não reduza à qualificação para o trabalho, que combata as diferentes formas de opressão que levam à exclusão de muitos jovens do cotidiano escolar e que valorize o profissional da educação.”. 
É diante do exposto e tendo por princípio a ideia de uma educação democrática que entendemos que postulados como os preconizados pela EsP não se sustentam. Evidenciar os elementos desta afirmação é o objetivo da próxima seção.

\section{A educação democrática frente à ESP}

Autodenominada de "Escola sem Partido", as ideias, objetivos e ações dessa organização colocam em questão, de forma preocupante, a partir do golpe de Estado de 2016, princípios democráticos e educacionais basilares que pareciam consolidados na sociedade brasileira. O próprio nome EsP já é preocupante, pois é um nome cuidadosamente escolhido para esconder as intenções supostamente apartidárias e não ideológicas da organização e, segundo Queiroz e Oliveira (2018) um nome que contribui para angariar a simpatia dos menos atentos aos reais e ocultos objetivos da organização. Preocupante, pois “[ ...] nega o acúmulo histórico da sociedade ocidental em torno das formas de aprimoramento e ganho de legitimidade da democracia" (QUEIROZ; OLIVEIRA, 2018, p. 34). Alguns estudos, assim, já demonstraram que a organização não é nem apartidária e nem livre de ideologia (ALGEBAILE, 2017; QUEIROZ; OLIVEIRA, 2018; ESPINOSA; QUEIROZ, 2017). O discurso da neutralidade tem a intenção de mirar e, consequentemente, aniquilar qualquer discurso crítico no campo educacional, mas a organização, na verdade, funciona através de uma rede com diversas articulações que abarcam principalmente políticos e grupos que mobilizam "valores liberais e conservadores" (QUEIROZ, OLIVEIRA, 2018), ou seja, marcados sim por ideologias e por partidos políticos específicos.

O fato é que, se por um lado a inconsistência teórica e jurídica das propostas da EsP silenciou o debate sobre o tema por, pelo menos, uma década, por outro, ela acabou se revelando após esse período uma “[...] organização especializada, que cumpre funções específicas de propaganda, mobilização e controle no âmbito de uma vertente partidária compromissada com a defesa de prerrogativas econômicas, políticas e socioculturais ultraconservadoras." (ALGEBAILE, 2017, p. 70). Na verdade, a EsP passou a existir por meio de “[...] uma poderosa teia de relações que surpreende pelo cunho conservador, com várias articulações e redes que perpassam por entidades da sociedade civil, instâncias religiosas e partidos políticos" (ESPINOSA; QUEIROZ, 2017, p. 49).

Dentre as articulações identificadas pelos pesquisadores que demonstram que a suposta neutralidade da EsP não existe, temos: a ligação do seu coordenador, Miguel Nagib, com o Instituto Millenium, entidade que propaga o pensamento liberal; a ligação da chamada 
bancada religiosa da Câmara dos Deputados, em Brasília, com representantes da EsP, que, com frequência, são convidados por parlamentares da bancada religiosa para defender, em audiências públicas, uma pauta que contempla a proibição do debate de gênero nas escolas, críticas aos movimentos e partidos de esquerda e que defenda a prevalência da educação familiar sobre a educação escolar (QUEIROZ; OLIVEIRA, 2018).

Sobre a suposta neutralidade da organização é relevante ainda a conclusão a que chegam Espinoza e Queiroz (2017) após acurada análise das redes sociais da organização.

O apartidarismo e a negação a vinculação ideológicas do Escola sem Partido caem totalmente por terra com a ARS (análise das redes sociais), e isso deve ser denunciado, pois sua associação ao que há de mais anacrônico na sociedade brasileira busca, sim, implementar uma ideologia obsoleta e inconstitucional em vários matizes. (ESPINOZA, QUEIROZ, 2017, p. 61).

Queiroz e Oliveira (2018), após análise pormenorizada dos textos da Constituição Federal de 1988 demonstram a inconstitucionalidade das propostas formuladas pela EsP por afrontarem os princípios da liberdade de ensinar, de divulgar o pensamento e do pluralismo de ideias e concepções pedagógicas, que permitirão ao indivíduo alcançar a plenitude da sua dignidade enquanto cidadão. O afrontamento se dá no momento em que a organização equipara pensamento crítico à doutrinação, insistindo na defesa do pensamento único, seu baluarte (RAMOS, 2018). Na verdade, “[...] criminaliza-se aquilo que é inerente ao processo educativo, ao ato pedagógico: confrontar ideias e compreensões sobre um mesmo assunto, debater, ajudar na elaboração do pensamento autônomo e fecundo mediado pelo conhecimento sistematizado" (RAMOS, 2017, p. 84).

Destaca-se da análise de Queiroz e Oliveira (2018) a seguinte conclusão:

Cotejando a análise dos artigos 206 e 205 com o artigo $1^{\circ}$ da Constituição, podemos concluir que para o indivíduo alcançar a plenitude da sua dignidade constitucionalmente assegurada, e de forma a poder manejar os instrumentos colocados à sua disposição como cidadão, é preciso que lhe seja assegurada uma educação que o dote desses predicados. Para tanto, a educação não prescindirá da liberdade de ensinar, divulgar o pensamento e do pluralismo de ideias e concepções pedagógicas, todos princípios constitucionais educacionais. E é justamente contra esses princípios que se insurge a EsP. E uma das fortes atuações da organização para neutralizar esses princípios é junto ao poder legislativo, seja ele no âmbito federal, estadual ou municipal, tanto que o site da EsP dispõe de modelos de anteprojetos de leis que podem ser apresentados pelos parlamentares interessados na matéria. (QUEIROZ; OLIVEIRA, 2018, p. 42).

A confusão entre pensamento crítico e doutrinação, que o discurso da EsP revela, e sua consequente afronta ao pluralismo de ideias e de concepções pedagógicas, podem ser verificadas em outra proposição da organização: a de incluir "[...] entre os princípios do ensino 
o respeito às convicções do aluno, de seus pais ou responsáveis, dando procedência aos valores de ordem familiar sobre educação escolar nos aspectos relacionados à educação moral, sexual e religiosa" (ESPINOSA; QUEIROZ, 2017, p. 52). A questão que se levanta aqui é que o discurso da primazia dos valores de ordem familiar sobre a educação escolar é utilizado, em última análise, para inviabilizar, na escola, o confronto de ideias e compreensões sobre determinado assunto, o que afastaria do processo educativo, por exemplo, o debate sobre aspectos relacionados à educação moral, sexual e religiosa. É por isso que a EsP também busca inviabilizar e criminalizar quaisquer iniciativas e propostas que abordem o tema da diversidade sexual ou que encampem o combate ao preconceito, ao sexismo e à LGBTfobia, além da ofensiva que a organização realiza contra os livros didáticos com abordagem crítica e reflexiva sobre esses temas (MATTOS et al, 2017). Para tanto, uma das estratégias é querer instituir via alteração da legislação, por exemplo, que se afixe em cada sala de aula um cartaz com os "Deveres do professor" com dizeres como: "o professor respeitará o direito dos pais a que seus filhos recebam a educação moral que esteja de acordo com suas próprias convicções" "; ou seja, há uma confusão entre "respeitar o direito dos pais" e impedir o debate sobre as diversas convicções. É nesse sentido que Espinoza e Queiroz (2017) afirmam que a organização dissemina a confusão entre espaço público e espaço privado. Isso significa a proibição aos educadores de instigarem a discussão sobre diferentes reflexões políticas, ideológicas e religiosas na construção do pensamento autônomo mediado pela sistematização do conhecimento. A negação disso, como busca a EsP, é um verdadeiro contrassenso se considerarmos a heterogeneidade que permeia a sala de aula, assim como toda a sociedade.

A crescente proposição nas casas legislativas (federal, estaduais e municipais) e, em alguns casos, aprovação de projetos de lei sedimentados na EsP deve alertar para o fato de que estão sendo questionados princípios de uma educação democrática que há até pouco tempo atrás pareciam consolidados. O alerta é importante ao passo que, segundo levantamento atualizado até 08 de janeiro de 2018, disponível no site do coletivo Professores Contra o Escola sem Partido, mais de 140 projetos de lei relacionados às ideias do Programa Escola sem Partido tramitavam nas casas legislativas, sendo grande parte deles do ano de 2017. Além disso, mesmo com a decisão liminar do ministro Luís Roberto Barroso, do Supremo Tribunal Federal (STF), que apontou a inconstitucionalidade da Lei ${ }^{\circ} 7.800 / 2016$, sedimentada no programa EsP, na prática, os efeitos deste programa não deixam de ser percebidos dentro e fora das escolas. Ao mesmo tempo em que crescia a quantidade de projetos de lei nas casas legislativas, surgiam

\footnotetext{
${ }^{8}$ Cartaz Deveres do professor disponível em: http://www.educarparasergrande.com.br/2017/03/10/escola-sempartido-segue-em-tramitacao-na-camara/. Acesso em: 03 jan. 2020.
} 
episódios de denúncias contra professores das escolas e universidades por "doutrinação ideológica"9 e, nas redes sociais, manifestações de apoiadores do programa, incentivando estudantes a filmar professores em supostas práticas de doutrinação ${ }^{10}$. Essas ações buscam promover a desqualificação da profissão docente e o incentivo, nas escolas, de práticas de denúncia e criminalização dos professores, a partir da ideia de que o professor seria um agente opressor e o aluno um ser passivo nas relações pedagógicas (RAMOS, 2017).

Katz (2017) também considera que, por meio de "investidas de poder" (praticadas em duas frentes: a construção de verdades que subsidiam o movimento nas suas afirmações e o mecanismo da denúncia), são praticadas, pela EsP, estratégias de dominação que acabaram por construir identidades docentes desejáveis, que funcionam como posições de sujeito a serem ocupadas pelos docentes. As "investidas de poder" da EsP sobre as condutas docentes são evidenciadas em, pelo menos, três publicações de autoria do coordenador do movimento e veiculadas no site da organização (escolasempartido.org): o cartaz Deveres do Professor, o artigo A ideologia de gênero no banco dos réus e a carta Mensagem de fim de ano do coordenador do Escola sem Partido ao militante disfarçado de professor. Ao analisar as três publicações estabelecendo paralelos entre elas e os PLs $n^{\circ}$ 867/2015 e $n^{\circ}$ 193/2016 e outros materiais divulgados pelo EsP, Melo (2017) identificou uma "cenografia discursiva" de combate, censura e perseguição ao profissional docente e o estímulo de "dispositivos paranoicos" em torno do ato de lecionar, ambos reveladores de um discurso de ódio à categoria e às práticas docentes, que desvalorizam a atividade e a imagem profissional do professor.

Infere-se que, segundo o exposto, as "investidas de poder", a "cenografia discursiva" de combate, censura e perseguição ao docente e o estímulo de "dispositivos paranoicos" em torno do ato de lecionar, também são propostas e ações da organização EsP que afrontam as normas constitucionais e infraconstitucionais sobre o tema educação, especialmente porque criam um antagonismo entre quem ensina e quem aprende na escola, e não contribuem para a valorização da profissão docente, pelo contrário, desqualificam e criminalizam posturas críticas e plurais desses profissionais.

O site da organização é um dos meios utilizados como estratégia para veicular denúncias e construir a ideia de que docentes e estudantes, na escola, estão em polos

\footnotetext{
${ }^{9}$ É o caso envolvendo Ana Caroline Campagnolo, defensora da EsP, que em 2017 (quando jovem e desconhecida estudante) processou uma professora por "perseguição ideológica" e, quando eleita deputa estadual pelo PSL de SC em 2019. Matéria disponível em: <https://www.brasildefato.com.br/2018/10/29/deputada-eleita-pelo-pslestimula-estudantes-a-denunciarem-professores/>. Acesso em: 07 de janeiro de 2019.

${ }^{10}$ Ana Caroline Campagnolo também estimulou estudantes a denunciarem professores supondo que estes fariam queixas político-partidárias em virtude da vitória do presidente Bolsonaro após as eleições de 2019. Matéria disponível em: <https://www.brasildefato.com.br/2018/10/29/deputada-eleita-pelo-psl-estimula-estudantes-adenunciarem-professores/>. Acesso em: 07 de janeiro de 2019.
} 
antagônicos: os professores como militantes doutrinadores e os estudantes como indivíduos completamente passivos e manipuláveis no processo de aprendizagem. Textos, mensagens e imagens veiculadas no site também são utilizadas para criar a ideia de que é necessário desconfiar dos professores, a exemplo das seções intituladas "Flagrando o doutrinador" e "Planeje sua denúncia".

Tais ações e propostas são um flagrante atentado aos princípios constitucionais e infraconstitucionais da liberdade de aprender e ensinar e do pluralismo de ideias e concepções pedagógicas. Além disso, um espaço que tem por princípio ensinar e valorizar o pluralismo de ideias e pensamento não pode ser transformado num ambiente de conflito entre os indivíduos que fazem parte desse processo. Como é possível ensinar liberdade e pluralismo de ideias quando se requer amordaçá-las?

Em síntese, a EsP é "[...] a antítese do sentido da escola a qual, por sua vez, se transformaria num tribunal ideológico que legitimaria e naturalizaria a violência”. (RAMOS, 2017, p. 85). Assim, “a pedagogia da confiança e do diálogo crítico é substituída pelo estabelecimento de uma nova função: estimular os alunos e seus pais a se tornarem delatores." (FRIGOTTO, 2017, p. 31).

\section{Considerações finais}

Buscou-se, na relação entre educação, sociedade e democracia, princípios que sustentam a ideia de uma educação democrática e de como estes estão refletidos na legislação brasileira, de modo a problematizar a EsP frente a esta educação demonstrando o antagonismo dos objetivos, das ideias e dos modos de atuação desta organização com os princípios democráticos, com os direitos e com as garantias fundamentais no campo da educação.

Diante do exposto, torna-se incontornável a crítica à organização EsP, uma vez que suas ideias, propostas e ações, de uma forma não democrática e ilícita perante a constituição brasileira, promovem e utilizam o estado de exceção para servir aos seus interesses, ameaçando a não garantia de uma educação democrática. A EsP e outros projetos sedimentados nas proposições desta organização violam vários preceitos da Constituição Federal de 1988, como a promoção do pleno desenvolvimento da pessoa, a sua liberdade de aprender e ensinar, o pluralismo de ideias e concepções pedagógicas no ambiente escolar e a valorização dos profissionais da educação escolar.

Assim, a EsP se somou às alterações constitucionais e reformas aprovadas em âmbito nacional, dando visibilidade a um conjunto de medidas e ações nefastas viabilizadas pela 
conjuntura política assentada no golpe de Estado de 2016, que comprometem a garantia da educação pública, universal, gratuita, laica, democrática e de qualidade para as novas gerações.

Espera-se que a decisão do STF no julgamento da ADPF 457 que afirmou a inconstitucionalidade da Lei ${ }^{\circ} 1.516 / 2015$, do Município de Novo Gama (GO), que proibiu a utilização de materiais didáticos que abordem questões de gênero e sexualidade nas escolas públicas municipais, possa inviabilizar a tramitação dos inúmeros projetos de leis sedimentados nas propostas da EsP já apresentados às casas legislativas nas três esferas, bem como constranger a proposição de novos projetos com esse teor. E, assim, conduzir a organização a ocupar lugar devidamente obscuro na galeria da história, acompanhado dos que trataram de pautar um conjunto de ideias nefastas, viabilizadas por tempos e agendas antidemocráticos, que impedem a educação brasileira de avançar na garantia dos direitos educacionais de sua população.

Aqui, vale destacar que o histórico brasileiro pelo direito à educação pública, gratuita e democrática, como enfatiza Rosa (2018, p. 51), “é uma luta permanente de estudantes, educadores e movimentos sociais em um processo lento, marcado por retrocessos em períodos autoritários." Neste sentido, temos que ficar atentos ao perigo antidemocrático que organizações do tipo EsP significam para o campo da educação. O espaço que esta organização e suas pautas obtiveram no cenário político e educacional brasileiro deve alertar para o fato de que é preciso manter a vigilância na defesa da educação democrática. Isso porque o ataque sempre pode assumir, nos diversos contextos, novas e perigosas roupagens.

\section{REFERÊNCIAS}

ALGEBAILE, Eveline. Escola sem Partido: o que é, como age, para que serve. In: FRIGOTTO, Gaudêncio (Org.). Escola "sem" Partido: Esfinge que ameaça a educação e a sociedade brasileira. Rio de Janeiro: LPP/UFRJ, 2017. p. 63-74.

BRASIL. Lei no 9.394, de 20 de dezembro de 1996. Diário Oficial [da] República Federativa do Brasil, Poder Legislativo, Brasília, DF, 23 dez. 1996. Disponível em: http://www2.camara.leg.br/legin/fed/lei/1996/lei-9394-20-dezembro-1996-362578-normapl.htm. Acesso: 30 dez. 2019.

BRASIL. Constituição da República Federativa do Brasil de 1988. Diário Oficial [da] República Federativa do Brasil, Poder Legislativo, Brasília, DF, 05 out. 1988. Disponível em: http://www.planalto.gov.br/ccivil_03/constituicao/douconstituicao88.pdf. Acesso em: 01 jan. 2019.

CUNHA, Luiz Antônio. Ensino médio: atalho para o passado. Educação \& Sociedade, Campinas, v. 38, n. 139, p. 373-384, abr./jun. 2017. Disponível em: 
http://dx.doi.org/10.1590/es0101-73302017176604. Acesso em: 24 dez. 2019.

DECLARAÇÃO UNIVERSAL DOS DIREITOS HUMANOS. Assembleia Geral das Nações Unidas em Paris de 10 dezembro 1948. Rio de Janeiro: UNIC, ago. 2009. Disponível em: https://nacoesunidas.org/wp-content/uploads/2018/10/DUDH.pdf. Acesso em: 26 dez. 2019.

DUBAR, Claude. La socialisation: construction des identités sociales et professionales. 3. ed. Paris: Armand Colin, 2000.

DURKHEIM, Émile. Educação e Sociologia. Tradução de Nuno Garcia Lopes. Lisboa: Edições 70, 2001.

ESPINOSA, Betty R. Solano; QUEIROZ, Felipe B. Campanuci. Breve análise sobre as redes do Escola sem Partido. In: FRIGOTTO, Gaudêncio (Org.). Escola "sem" Partido: esfinge que ameaça a educação e a sociedade brasileira. Rio de Janeiro: UFRJ, 2017. p. 49-62.

FERRETI, Celso João; SILVA, Monica Ribeiro da. Reforma do ensino médio no contexto da medida provisória $n^{\circ}$ 746/2016, currículo e disputas por hegemonia. Educação \& Sociedade, Campinas, v. 38, n. 139, p. 385-404, abr./jun. 2017. Disponível em: http://dx.doi.org/10.1590/es0101-73302017176607. Acesso em: 20 dez. 2019.

FRIGOTTO, Gaudêncio. A disputa da educação democrática em sociedade antidemocrática. In: PENNA, Fernando; QUEIROZ, Felipe; FRIGOTTO, Gaudêncio (Orgs.). Educação democrática: antídoto ao Escola sem Partido. Rio de Janeiro: LPP/UFRJ, 2018. p. 15-32.

FRIGOTTO, Gaudêncio. A gênese das teses do Escola sem Partido: esfinge e ovo da serpente que ameaçam a sociedade e a educação. In: FRIGOTTO, Gaudêncio (Org.). Escola "sem" Partido: esfinge que ameaça a educação e a sociedade brasileira. Rio de Janeiro: LPP/UFRJ, 2017. p. 17-34.

KATZ, Elvis Patrik. Escola Sem Partido: uma análise das investidas de poder sobre as identidades docentes. 2017. 142 f. Dissertação (Mestrado em Educação) - Universidade Federal do Rio Grande, Rio Grande, 2017.

MATTOS, Amana et al. Educação e liberdade: apontamentos para um bom combate ao Projeto de Lei Escola sem Partido. In: FRIGOTTO, Gaudêncio (org.). Escola "sem" Partido: esfinge que ameaça a educação e a sociedade brasileira. Rio de Janeiro: LPP/UFRJ, 2017. p. 87-104.

MELO, Fabiany Carneiro de. Quando lecionar pode virar crime: o movimento "Escola sem Partido" sob uma ótica discursiva. 2017. Dissertação (Mestrado em Estudos de Linguagem) Universidade Federal Fluminense, Niterói, 2017.

MOTTA, Vânia Cardoso da; FRIGOTTO, Gaudêncio. Por que a urgência da reforma do ensino médio? Medida Provisória $n^{\circ}$ 746/2016 (Lei no 13.415/2017). Educação \& Sociedade, Campinas, v. 38, n. 139, p. 355-372, abr./jun. 2017. Disponível em: http://dx.doi.org/10.1590/es0101-73302017176606. Acesso em: 20 dez. 2019.

ORSO, Paulino José. Escola "sem" Partido ou um partido a serviço da burguesia? In: BATISTA, Eraldo Leme; ORSO, Paulino José; LUCENA, Carlos. (Orgs.). Escola sem 
partido ou a escola da mordaça e do partido único a serviço do capital. Uberlândia: Navegando Publicações, 2019. p. 131-162.

PENNA, Fernando de Araujo. Construindo estratégias para uma luta pela educação democrática em tempos de retrocessos. In: PENNA, Fernando; QUEIROZ, Felipe; FRIGOTTO, Gaudêncio (Orgs.). Educação democrática: antídoto ao Escola sem Partido. Rio de Janeiro: LPP/UFRJ, 2018. p. 111-130.

PENNA, Fernando de Araujo. O Escola sem Partido como chave de leitura do fenômeno educacional. In: FRIGOTTO, Gaudêncio (org.). Escola "sem" Partido: esfinge que ameaça a educação e a sociedade brasileira. Rio de Janeiro: LPP/UFRJ, 2017. p. 35-48.

PETITAT, André. Produção da escola/produção da sociedade: análise sócio-histórica de alguns momentos decisivos da evolução escolar no ocidente. Tradução de Eunice Gruman. Porto Alegre: Artes Médicas, 1994.

PRONER, Carol; STROZAKE, Ney. Frente Brasil de juristas pela democracia em defesa do devido processo legal. In: PRONER, Carol et al. (Org.). Comentários a uma sentença anunciada: o Processo Lula. Bauru: Canal 6, 2017. p. 14.

QUEIROZ, Felipe B. Campanuci; OLIVEIRA, Rafael Bastos Costa de. Liberdade para a democracia: considerações sobre a inconstitucionalidade da Escola sem Partido. In: PENNA, Fernando; QUEIROZ, Felipe; FRIGOTTO, Gaudêncio (Orgs.). Educação democrática: antídoto ao Escola sem Partido. Rio de Janeiro: LPP/UFRJ, 2018. p. 33-50.

RAMOS. Marise Nogueira. Introdução. In: PENNA, Fernando; QUEIROZ, Felipe; FRIGOTTO, Gaudêncio (Orgs.). Educação democrática: antídoto ao Escola sem Partido. Rio de Janeiro: LPP/UFRJ, 2018. p. 7-13.

RAMOS, Marise Nogueira. Escola sem Partido: a criminalização do trabalho pedagógico. In: FRIGOTTO, Gaudêncio (Org.). Escola "sem" Partido: Esfinge que ameaça a educação e a sociedade brasileira. Rio de Janeiro: UFRJ, LPP, 2017. p. 75-86.

ROSA, Russel Teresinha Dutra da. Direito à educação democrática: conquistas legais e ameaças In: PENNA, Fernando; QUEIROZ, Felipe; FRIGOTTO, Gaudêncio (Orgs.).

Educação democrática: antídoto ao Escola sem Partido. Rio de Janeiro: LPP/UFRJ, 2018. p. 51-74.

SAVIANI, Dermeval. O Plano de Desenvolvimento da Educação: Análise do projeto do MEC. Educação \& Sociedade, Campinas, v. 28, n. 100, out. 2007. p. 1231-1255.

SAVIANI, Dermeval. Neo-liberalismmo ou pós-liberalismo? Educação pública, crise do Estado e democracia na América Latina. In: VELLOSO, Jacques; et al. Estado e educação. Campinas: Papirus, 1992. p. 9-30.

SAVIANI, Dermeval. Escola e democracia: teorias da educação, curvatura da vara, onze teses sobre educação e política. 23. ed. São Paulo: Cortez, 1991.

STF. Medida cautelar na ação direta de inconstitucionalidade $n^{\circ}$ 5537. Requerente: CONTEE. Requerido: Assembleia Legislativa do Estado de Alagoas. Relator: Ministro Luís Roberto 
Barroso. Brasília, DF, 21 de março de 2017. Diário da Justiça Eletrônico: Brasília, DF, 22 mar. 2017. Disponível em: https://bit.ly/2AlRjIm. Acesso em: 09 dez. 2019.

TOMMASELLI, Guilherme Costa Garcia. Escola sem partido: indícios de uma educação autoritária. 2018. 199 f. Tese (Doutorado em Educação) - Universidade Estadual Paulista Júlio de Mesquita Filho, Presidente Prudente, 2018.

\section{SOBRE OS AUTORES:}

\section{Charles Immianovsky}

Doutorando em Educação - FURB; Professor do Instituto Federal Catarinense (IFC) - Brasil; Doutorando do Programa de Pós-Graduação em Educação da Universidade Regional de Blumenau (FURB); Membro do Grupo de Pesquisa Arte e Estética na Educação (FURB - SC). E-mail: charles.ismirnov@gmail.com

(iD https://orcid.org/0000-0002-4682-4959

\section{Rita de Cássia Marchi}

Pós Doutora em Sociologia da Infância - Universidade do Minho. Doutora em Sociologia Política - UFSC/PARIS V; Professora do Programa de Pós-Graduação em Educação da Universidade Regional de Blumenau (FURB) - Brasil; Líder do Grupo de Pesquisa Núcleo de Estudos Interdisciplinar da Criança e do Adolescente - NEICA (FURB - SC). Email: atoseditora@gmail.com

iD http://orcid.org/0000-0002-3408-2732

\section{Carla Carvalho}

Doutora em Educação - UFPR; Professora do Programa de Pós-Graduação em Educação da Universidade Regional de Blumenau (FURB) - Brasil; Líder do Grupo de Pesquisa Arte e Estética na Educação (FURB - SC). E-mail: ca_carvalho@icloud.com

(iD https://orcid.org/0000-0002-1402-7920 